\title{
EFFICIENT MARKET HYPOTHESIS: CASE OF THE CROATIAN CAPITAL MARKET
}

\author{
Ivan Novak *
}

\begin{abstract}
This study employs a quantile auto-regression approach in order to examine the market efficiency of the Croatian stock market using daily CROBEX returns in the period of 2000-2019. Auto-regression model AR (1) confirmed the significant influence of the previous day return, nevertheless model suffered from heteroscedasticity. In order to avoid the OLS restrictions, this paper applies the quantile unit root approach. According to the results of the quantile unit root weak form of the efficient market, the hypothesis was rejected. Endogenous shocks were found to be persistent and asymmetric. Model results stayed robust regardless of the structural break. This predictable behavior of CROBEX may enable investors to obtain abnormal profits.
\end{abstract}

KEYWORDS: Efficient market hypothesis, Croatia, quantile regression, unit root

\section{INTRODUCTION}

Recognizing market patterns remains one of the most daunting achievements in financial theory and practice. Considering profits and risk ratio investors seek to optimize their portfolios. With the development of information technology, investors are given opportunities for better decision-making tools and faster trading.

Theory of the efficient market hypothesis (EMH) was formulated in the 1960s by Paul Samuelson and Eugene Fama. There are two important implication of the efficient market hypothesis (EMH). All price movement is random and all fundamental information is already included in the price of the financial

\footnotetext{
* Assistant professor at Faculty of Economics and Business, University of Zagreb; inovak1@ net.efzg.hr
} 
asset. Developers of the EMH, Fama and Samuelson argued that the random market price behavior was the result of rational decision making. Depending on its strength it is possible to differentiate among variations of the efficient market hypothesis (EMH). The strongest form of the EMH states that stock market prices incorporate all relevant information (public and private). The semi-strong form of the EMH states that the stock market prices incorporate all publicly available date and finally the weak form of the EMH stated it is impossible to predict the future stock price movements according to their historical values ${ }^{1}$.

In countries with communist background stock exchanges are still found to be very speculative. A modest debt of the stock market and few big investors may result in the lack of market efficiency which is consequently reflected in price patterns. If the market information efficiency is low investors may obtain abnormal and systemic returns. Using quantile regression approach this paper examines the efficiency of the Croatian stock market returns.

The remainder of the paper is organized as follows. The second section of the paper contains a literature overview dealing with the efficient market hypothesis. The third section of the paper describes data and methodology. The fourth section of the paper is presenting empirical results and discussion and finally, the conclusion summarizes papers' results and consequent implications for decision makers.

\section{LITERATURE REVIEW}

There have been many attempts to examine the efficiency of the European emerging capital markets with the earliest starting in 1988. One of the recent papers examined 15 European emerging capital markets and for comparative reasons also included few developed markets (Greece, Portugal and the United Kingdom). The author applied rolling window variance ratio test with bootstrapping p-values for daily returns for the period 2000-2009. Stock markets in Estonia, Ukraine, and Malta were the least efficient while the stock markets in Poland, Hungary, the United Kingdom, and Turkey were the most efficient. Hungarian stock market was at least weak form efficient in the period from 1991 to 2005, Polish stock market was at least weak form efficient in the period from 1993 to 2007 and Turkish stock market efficiency was highly dependent on liquidity. Even though markets in Poland, Czech Republic, Estonia, Lith-

\footnotetext{
1 Tsenkov, V., \& Stoitsova-Stoykova, A. (2017). The Impact of the Global Financial Crisis on the market efficiency of capital markets of southeast Europe. International Journal of Contemporary Economics and Administrative Sciences, 7(1-2), 31-57.
} 
uania, Greece, and Portugal were increasing their efficiency over time financial crisis in 2008 has triggered deviations from the weak form efficiency for Croatia, Hungary, Poland, Portugal, Slovakia, and UK markets. Nevertheless, Greece, Romania, Latvia, Russia, and Turkey were not affected by the global financial crisis in 2008. The author emphasized that rejecting the weak form efficiency hypothesis may lead traders to question the value of technical analysis and automatic trading strategies. ${ }^{2}$

Similarly, emphasizing the effect of the latest global financial crisis efficiency of the eleven stock markets in South East European countries (Croatia, Slovenia, Hungary, Czech Republic, Slovakia, Poland, Estonia, Latvia, Lithuania, Bulgaria, Romania, Bosnia and Herzegovina, Serbia, Montenegro, Northern Macedonia, Georgia, Kazakhstan, Moldova, Ukraine and Russia) was tested for the period 2005-2015. Time series were divided in pre-crisis, during the crisis and the after the crisis period. In order to test the efficiency of these markets, authors applied the autocorrelation analysis, the Run test and the GARCH family models. Results about the SEE capital markets' efficiency were heterogeneous. In the case of Bosnia and Herzegovina, Bulgaria, Croatia, Greece, Northern Macedonia, Serbia and Romania weak form efficient hypothesis was rejected for the entire period. Slovenia's' stock market was found efficient regardless of the period. Out of eleven SEE capital markets four of them (Bosnia and Herzegovina, Greece, Slovenia, and Turkey) were found to be at least weak form efficient in at least one of the observed period. Furthermore, in the period of crisis, several markets decreased their efficiency even more: Bosnia and Herzegovina, Slovenia, Turkey, and Greece. Croatia and Greece markets were found to be very low efficient without improvement in the after crisis period ${ }^{3}$.

Another paper examined the efficiency of 20 post-communist stock markets in the period 2008-2010. In order to increase the robustness of the results, authors used various approaches: January effect, Unit root test, Variance ratio test, Runs test and Filter rules test. In the case of Bulgaria, Czech Republic, Croatia, Georgia, Hungary, Estonia, Kazakhstan, Latvia, Lithuania, Poland, Romania, Slovenia, and Slovakia stock markets were found to be at least weak form efficient while in the case of Bosnia and Herzegovina, Serbia, Montenegro, Northern Macedonia, Moldova, Ukraine and Russia efficient market hypotheses was rejected. Due to heterogeneous results, the twofold recommendation was given for decisions makers. If the efficient market hypothesis holds

2 Smith, G. (2012). The changing and relative efficiency of European emerging stock markets. The European Journal of Finance, 18(8), 689-708.

3 Tsenkov, V., \& Stoitsova-Stoykova, A. (2017). The Impact of the Global Financial Crisis on the market efficiency of capital markets of south east Europe. International Journal of Contemporary Economics and Administrative Sciences, 7(1-2), 31-57. 
investors should use more passive trading strategies and if the efficient market hypothesis doesn't hold investors should use more active trading strategies ${ }^{4}$. On the contrary, to this result for the Czech Republic, another author in his paper applying the state space approach managed to formulate a strategy beating the Czech Republic stock market and therefore violate the assumption of the efficient market hypothesis ${ }^{5}$.

One paper studied exclusively Serbian stock market efficiency. In order to confirm the lack of market efficiency authors used Dickey Fuller, Phillips Peron (PP) and Run Test. They believe the lack of market efficiency resulted from the non-symmetric information, high transaction costs, few highly liquid stocks and the lack of strong institutional investors ${ }^{6}$.

Seasonal anomalies were studied in eleven Central and Eastern European markets (Romania, Hungary, Russia, Latvia, Estonia, Lithuania, Czech Republic, Slovakia, Poland, Slovenia, and Bulgaria) in the period 2000-2015. Using GARCH authors confirmed many seasonal anomalies ("day of the week and weekend", "week of the month", "first week of the month", "month of the year and January effect") of the returns and volatility of the examined markets and therefore rejected the efficient market hypothesis. Nevertheless due to transaction costs only profitable anomaly was the January effect ${ }^{7}$. Another two papers examined specifically Romanian market. The first paper studied the "day of the week" effect and revealed no breach of the efficient market hypothesis ${ }^{8}$. The second paper analyzed intraday price movements confirming deviations from the efficient market hypothesis. However profitable trading was not possible using popular technical indicators ${ }^{9}$. Another paper investigated several Balkan countries (Bosnia \& Herzegovina, Bulgaria, Croatia, Greece, Slovenia, and Romania) in the period 2012-2016 testing specifically for "day of the

4 Dragotă, V., \& Tुilică, E. V. (2014). Market efficiency of the Post Communist East European stock markets. Central European Journal of Operations Research, 22(2), 307-337.

5 Svoboda, M. (2016). Stochastic model of short-term prediction of stock prices and its profitability in the Czech Stock Market.

6 Stakić, N., Jovancai, A., \& Kapor, P. (2016). The efficiency of the stock market in Serbia. Journal of Policy Modeling, 38(1), 156-165.

7 Andries, A., Ihnatov, I., \& Sprincean, N. (2017). Do seasonal anomalies still exist in central and eastern european countries? a conditional variance approach. Romanian Journal of Economic Forecasting, 20(4), 60-83.

8 Marcu, N., Dobrota, C. E., \& Antoneac, R. (2017). An Investigation of the Day-of-the-week Effect in Conditional Variance at the Bucharest Stock Exchange. Journal for Economic Forecasting, (2), 124-134.

9 Anghel, D. G. (2017). Intraday Market Efficiency for a Typical Central and Eastern European Stock Market: The Case of Romania. Romanian Journal of Economic Forecasting, 20(3), 88. 
weak" anomaly. The effect was not confirmed in any of the selected markets except Croatia. CROBEX stock index was found to be predictable with the potential of retrieving abnormal returns.

Furthermore, the Croatian capital market had 10 investment funds declaring to use active trading strategies aiming to outperform the market returns. Authors of the paper tested the relationship between investment funds and daily value of CROBEX. Johansen bivariate co-integration test was used to determine the long term relationship between investment funds and daily CROBEX data in the period from 1999 to 2007. Since results confirmed co-integration relationships in four investment funds authors further examine the autocorrelation property of CROBEX. CROBEX was found to be dependent on the previous values. This dependence was considered to be the result of low market liquidity. ${ }^{10}$

Most of the papers examining the efficiency of the stock markets focus on studying the average value and variance pattern while the quantile regression approach examines the characteristics of endogenous shocks (effects considering the sign and magnitude).

Quantile approach was used to examine eight transition economies using weekly log stock market prices for the period 2000-2015. According to the results, stock market prices in Croatia, Czech Republic, Hungary, Lithuania, and Poland were found to be non-stationary therefore enabling investors to attain abnormal returns. This result was consistent with conventional unit root tests result for log weekly levels. Nevertheless, contrary to the conventional unit root test results quantile approach for Bulgaria, Romania and Russia found their prices to be stationary. Structural breaks often increase unit root test bias toward the null hypothesis ${ }^{11}$. Quantile approach is not restricted to a specific regime and may potentially enhance the accuracy of stationarity testing ${ }^{12}$. Quantile unit root testing was developed by Koenker and Xiao. ${ }^{13}$ Using daily $\log$ returns in the period 2000-2019 this paper employs rather an innovative method in testing the efficient market hypothesis for the Croatian stock market.

10 Čondić Jurkić, I. i Dadić, T. (2008). Investicijski fondovi na hrvatskom tržištu kapitala: strategije trgovanja i kretanje tržišta. Zbornik Ekonomskog fakulteta u Zagrebu, 6 (1), 61-77. Downloaded from https://hrcak.srce.hr/30946

11 Perron, P. The great crash, the oil price shock, and the unit root hypothesis. Econometrica, v. 57 , p. 1361-1401, 1989.

12 Hosseinkouchack, M., \& Wolters, M. H. (2013). Do large recessions reduce output permanently?. Economics Letters, 121(3), 516-519.

13 Koenker, R. \& Xiao, Z. (2004). Unit Root Quantile Autoregression Inference. Journal of the American Statistical Association, 99(467), 775-787. Retrieved from http://www.jstor.org/ stable/27590447 


\section{METHODOLOGY AND DATA}

Daily frequency of the CROBEX data for the period of January 2000 to March 2019 was collected from the web site of the Croatian stock exchange market "Zagrebačka burza"14. CROBEX time series was converted to the $4831 \mathrm{log}$ returns according to the equation (1)

$$
l c r_{t}=\ln \left(c r_{t} / c r_{t-1}\right)
$$

where:

$l c r_{t}$ - daily log return of CROBEX

$c r_{t}-$ CROBEX value for $\mathrm{t}$

$\mathrm{cr}_{t-1}-$ CROBEX value for $\mathrm{t}-1$.

Auto-regression model was defined according to the equation (2)

$$
l c r_{t}=\alpha+\beta l c r_{t-i}+\varepsilon_{t}
$$

If $\beta=0$ then the null hypothesis is not rejected and the market could be considered at least weak form efficient. If the $\beta>0$ the null hypothesis is rejected and the market could be considered non-efficient. Nevertheless if time series exhibits clusters of volatility coefficient estimates may be biased. Therefore the quantile auto-regression approach is more suitable. Quantile auto-regression process is defined by the following equation (3)

$$
Q_{l c r_{t}}\left(\tau \mid l c r_{t-1}\right)=\beta_{1}(\tau) \cdot l c r_{t-1}+\varepsilon(\tau)
$$

where $Q_{l c r_{t}}\left(\tau \mid l c r_{t-1}\right)$ stands for $\tau$-quantile of the log returns, $\varepsilon(\tau)$ stands for quantile of the residual $\left(\varepsilon_{t}\right)$ therefore the endogenous shock, while $\beta_{1}(\tau)$ stands for quantile dependent coefficient of the lagged log return.

Residual $\varepsilon(\tau)$ in its sign and magnitude reflect the endogenous shock, where positive shocks reflect increasing log returns in the Croatian stock market and negative shocks reflect decreasing log returns in the Croatian stock market.

Standard errors are calculated according to Hall and Sheather rules with the assumption of local linearity of the conditional quantile function. More details about quantile regression can be found in the work of Koenker and Xiao ${ }^{1516}$.

\footnotetext{
14 https://www.zse.hr/default.aspx?id=44101\&index=CROBEX

15 Koenker, R. \& Xiao, Z. (2004). Unit Root Quantile Autoregression Inference. Journal of the American Statistical Association, 99(467), 775-787. Retrieved from http://www.jstor.org/ stable/27590447

16 Koenker, R. \& Xiao, Z. (2006). Quantile Autoregression, Journal of the American Statistical Association, 101:475, 980-990, doi: 10.1198/016214506000000672
} 


\section{EMPIRICAL RESULTS AND DISCUSSION}

In order to examine the characteristics of the log returns of CROBEX in the period of January 2000 to March 2019 descriptive results are given in Table 1.

Table 1 Descriptive data of CROBEX log returns January 2000 - March 2019

\begin{tabular}{|c|c|c|c|c|c|c|}
\hline Min & Median & Mean & Max & Jarque Bera & Skewness & Kurtosis \\
\hline$-0,1076363$ & 0,0000518 & 0,0001767 & 0,1477896 & $\begin{array}{c}54206 \\
<2,2 \mathrm{e}-16\end{array}$ & 0,078375 & 19,409 \\
\hline
\end{tabular}

Source: Authors' calculation

Results in Table 1 and Appendix 1 indicate clusters of volatility and deviations from the normal distribution.

Even though conventional unit root tests do not perform well under these circumstances ADF, PP and KPSS test results are given for comparison in Table 2.

Table 2 Conventional unit root test for CROBEX log returns January 2000 March 2019

\begin{tabular}{|l|c|}
\hline Unit root test & p-value \\
\hline Augmented Dickey-Fuller Test & $<0,010$ \\
\hline Kwiatkowski-Phillips-Schmidt-Shin (KPSS) & 0,083 \\
\hline Phillips-Perron & $<0,010$ \\
\hline
\end{tabular}

Source: Authors' calculation

Results of the unit root tests for the log returns of the CROBEX in the period of January 2000 to March 2019 indicate stationarity of the data. Furthermore to examine the autocorrelation property of the CROBEX $\log$ returns from January 2000 to March 2019 model estimation is given in Table 3.

Table 3 Estimates of the auto-regression model January 2000 - March 2019

\begin{tabular}{|l|c|c|c|c|}
\cline { 2 - 5 } \multicolumn{1}{c|}{} & Coeff. & Std. Error & t-value & p-value \\
\hline (Intercept) & 0,0001543 & 0,0001716 & 0,899 & 0,369 \\
\hline $\mathrm{y}[-1]$ & 0,0595331 & 0,0143321 & 4,154 & 0,000 \\
\hline Box-Ljung test & & & 0,000 \\
\hline ARCH LM-test & & & 0,000 \\
\hline Jarque Bera Test & \multicolumn{3}{|l}{} & \\
\cline { 1 - 2 } & & &
\end{tabular}

Source: Authors' calculation 
Result of the auto-regression model AR (1) confirms the significant influence of the previous day returns but nevertheless model suffered from autocorrelation, heteroscedasticity while residuals were not normally distributed. In order to avoid the breach of OLS assumptions, these papers apply the quantile regression approach.

Results of the quantile unit root are given in Table 4.

Table 4 Estimates of the quantile auto-regression model January 2000 - March 2019

\begin{tabular}{|c|c|c|c|c|c|c|c|}
\hline $\mathrm{Q}(\tau)$ & $\alpha_{0}(\tau)$ & \multicolumn{1}{c|}{ t-stat } & $\mathrm{p}$ & $\alpha_{1}(\tau)$ & t-stat & $\mathrm{p}$ & Half-life \\
\hline 0,1 & $-0,01045$ & $-31,5608$ & 0,000 & 0,08453 & 3,13191 & 0,001 & 0,28055 \\
\hline 0,2 & $-0,00576$ & $-29,6039$ & 0,000 & 0,08991 & 8,29918 & 0,000 & 0,28774 \\
\hline 0,3 & $-0,00317$ & $-23,7718$ & 0,000 & 0,07198 & 6,53055 & 0,000 & 0,26342 \\
\hline 0,4 & $-0,00131$ & $-11,267$ & 0,000 & 0,05398 & 8,97475 & 0,000 & 0,23745 \\
\hline 0,5 & 0,00015 & 1,36697 & 0,171 & 0,06249 & 7,52268 & 0,000 & 0,24999 \\
\hline 0,6 & 0,00177 & 13,95294 & 0,000 & 0,07228 & 7,23937 & 0,000 & 0,26383 \\
\hline 0,7 & 0,00379 & 26,60315 & 0,000 & 0,06879 & 5,96757 & 0,000 & 0,25896 \\
\hline 0,8 & 0,00620 & 32,51699 & 0,000 & 0,06891 & 4,35588 & 0,000 & 0,25912 \\
\hline 0,9 & 0,01089 & 36,27093 & 0,000 & 0,05551 & 2,24035 & 0,025 & 0,23974 \\
\hline
\end{tabular}

Source: Authors' calculation

According to the results of the quantile unit root in Table 4 and Appendix 2 $\log$ returns of the CROBEX index from January 2000 to March 2019 exhibit asymmetry. Extreme negative shocks last longer than extreme positive shocks. On the 5\% level significance autoregressive coefficients differ from zero indicating some level of persistence in each quantile. If the market is efficient each event causing deviations in the log returns of the stock market should be transitory and autocorrelation coefficient should not be significant. Therefore the log returns of the Croatian stock market from January 2000 to March 2019 violate the weak form of the efficient market hypothesis.

Furthermore, since structural breaks may significantly influence the results it is beneficial to carry out some type of robustness check. According to mean and variance change point detection function ${ }^{17}$ recognized one structural break on 9th December 2012 (see appendix 1). This structural break was mostly attributed to a change in volatility. Prior to and during to global financial crisis in 2008 CROBEX log returns exhibit much higher volatility. In the after crisis

17 Chen, J. and Gupta, A. K. (2000) Parametric statistical change point analysis, Birkhauser 
period CROBEX log returns exhibit much less volatility, therefore, reducing the risk for investors.

In order to examine the characteristics of the log returns of the CROBEX in the period of January 2000 to December 2011 descriptive results are given in Table 5 .

Table 5 Descriptive data of CROBEX log returns January 2000 - December 2011

\begin{tabular}{|c|c|c|c|c|c|c|}
\hline Min & Median & Mean & Max & Jarque Bera & Skewness & Kurtosis \\
\hline$-0,1076363$ & 0,0001254 & 0,0002819 & 0,1477896 & $\begin{array}{c}16350 \\
(<2,2 \mathrm{e}-16)\end{array}$ & 0,061449 & 14,387 \\
\hline
\end{tabular}

Source: Authors' calculation

Results in Table 5 indicate that CROBEX log return series deviates from the normal distribution in the first subsample in the period from January 2000 to December 2011.

Even though conventional unit root tests do not perform well under these circumstances ADF, PP i KPSS test results are given for comparison in Table 6.

Table 6 Conventional unit root test for CROBEX log returns, January 2000 December 2011

\begin{tabular}{|l|c|}
\hline Unit root test & p-value \\
\hline Augmented Dickey-Fuller Test & $<0,010$ \\
\hline Kwiatkowski-Phillips-Schmidt-Shin (KPSS) & 0,074 \\
\hline Phillips-Perron & $<0,010$ \\
\hline
\end{tabular}

Source: Authors' calculation

Results of the unit root tests for the log returns of the CROBEX in the period of January 2000 to December 2011 indicate stationarity of the data. Furthermore to examine the autocorrelation property of the CROBEX log returns in the period from January 2000 to December 2011 model estimation is given in Table 7. 
Table 7 Estimates of the auto-regression model, January 2000 - December 2011

\begin{tabular}{|l|c|c|c|c|}
\cline { 2 - 5 } \multicolumn{1}{c|}{} & Coeff. & Std. Error & t-value & p-value \\
\hline (Intercept) & 0,0002463 & 0,0002623 & 0,939 & 0,347 \\
\hline y[-1] & 0,0580206 & 0,0181133 & 3,203 & 0,001 \\
\hline Box-Ljung test & & & 0,022 \\
\hline ARCH LM-test & & & $<2,2 \mathrm{e}-16$ \\
\hline Jarque Bera Test & & & $<2,2 \mathrm{e}-16$ \\
\cline { 4 - 5 } & & &
\end{tabular}

Results of the AR (1) model of the first subsample confirmed the full sample diagnostics and therefore quantile auto-regression approach was applied (see Table 7).

Table 8 Estimates of the quantile auto-regression model, January 2000 - December 2011

\begin{tabular}{|c|c|c|c|c|c|c|c|}
\hline $\mathrm{Q}(\tau)$ & \multicolumn{1}{c|}{$\alpha_{\mathbf{0}}(\tau)$} & $\mathrm{t}-$-stat & $\mathrm{p}$ & $\alpha_{1}(\tau)$ & $\mathrm{t}-$ stat & $\mathrm{p}$ & Half-life \\
\hline 0,1 & $-0,01347$ & $-24,7023$ & 0,000 & 0,09439 & 2,51164 & 0,012 & 0,293667 \\
\hline 0,2 & $-0,00757$ & $-26,0889$ & 0,000 & 0,11034 & 5,50553 & 0,000 & 0,314468 \\
\hline 0,3 & $-0,00407$ & $-15,7623$ & 0,000 & 0,07379 & 11,9119 & 0,000 & 0,265927 \\
\hline 0,4 & $-0,00157$ & $-8,03439$ & 0,000 & 0,05611 & 4,67472 & 0,000 & 0,240639 \\
\hline 0,5 & 0,00025 & 1,42906 & 0,153 & 0,05974 & 5,40149 & 0,000 & 0,245993 \\
\hline 0,6 & 0,00253 & 11,07035 & 0,000 & 0,06352 & 4,07487 & 0,000 & 0,251468 \\
\hline 0,7 & 0,00489 & 22,75378 & 0,000 & 0,06273 & 4,47862 & 0,000 & 0,250332 \\
\hline 0,8 & 0,0083 & 27,34932 & 0,000 & 0,06508 & 3,44946 & 0,000 & 0,253701 \\
\hline 0,9 & 0,01378 & 29,82625 & 0,000 & 0,06228 & 2,53205 & 0,011 & 0,249682 \\
\hline
\end{tabular}

Source: Authors' calculation

According to the results of the quantile unit root in Table 8 and Appendix 3 log returns of the CROBEX index from January 2000 to December 2011 exhibit asymmetry. Extreme negative shocks last longer than extreme positive shocks. Higher shocks last longer than smaller shocks and therefore creating a typical U-shape of the autocorrelation coefficients. On the 5\% level significance, autoregressive coefficients indicate some level of persistence in each quantile. Therefore the log returns of the Croatian stock market from January 2000 to December 2011 violate the weak form of the efficient market hypothesis.

In order to examine the characteristics of the log returns of the CROBEX in the period of December 2011 to March 2019 descriptive results are given in Table 9. 
Table 9 Descriptive data of CROBEX log returns December 2011 - March 2019

\begin{tabular}{|c|c|c|c|c|c|c|}
\hline Min & Median & Mean & Max & Jarque Bera & Skewness & Kurtosis \\
\hline$-0,03111$ & $-0,00004536$ & 0,00000049 & 0,03389 & $\begin{array}{c}996.56 \\
<2,2 \mathrm{e}-16\end{array}$ & 0,25641 & 6,7149 \\
\hline
\end{tabular}

Source: Authors' calculation

Results in Table 9 indicate that CROBEX log return series deviates from the normal distribution in the second subsample in the period from January 2000 to December 2011.

Even though conventional unit root tests do not perform well under these circumstances ADF, PP i KPSS test results are given for comparison in Table 10.

Table 10 Conventional unit root test for CROBEX log returns, December 2011 March 2019

\begin{tabular}{|l|r|}
\hline Unit root test & p-value \\
\hline Augmented Dickey-Fuller Test & $<0,010$ \\
\hline Kwiatkowski-Phillips-Schmidt-Shin (KPSS) & 0,100 \\
\hline Phillips-Perron & $<0,010$ \\
\hline
\end{tabular}

Source: Authors' calculation

Results of the unit root tests for the log returns of the CROBEX in the period from December 2011 to March 2019 indicate stationarity of the data. Furthermore to examine the autocorrelation property of the CROBEX log returns in the period from December 2011 to March 2019 model estimation is given in Table 11.

Table 11 Estimates of the auto-regression model, December 2011 - March 2019

\begin{tabular}{|c|c|c|c|c|}
\hline & Coeff. & Std. Error & t-value & p-value \\
\hline (Intercept) & $1.955 \mathrm{e}-06$ & $1.331 \mathrm{e}-04$ & 0.015 & 0.98829 \\
\hline $\mathrm{y}[-1]$ & $7.417 \mathrm{e}-02$ & $2.349 \mathrm{e}-02$ & 3.157 & 0.00162 \\
\hline Box-Ljung test & & & & $1,08 \mathrm{E}-03$ \\
\hline ARCH LM-test & & & & $<2.2 \mathrm{e}-16$ \\
\hline Jarque Bera Test & & & & $<2,2 \mathrm{e}-16$ \\
\hline
\end{tabular}

Source: Authors' calculation 
Results of the AR (1) model in for the second subsample confirmed the results of the full sample and the first subsample and therefore quantile auto-regression approach was applied (see Table 11).

Table 12 Estimates of the quantile auto-regression model, December 2011 March 2019

\begin{tabular}{|c|c|c|c|c|c|c|c|}
\hline $\mathrm{Q}(\tau)$ & $\alpha 0(\tau)$ & $\mathrm{t}$-stat & $\mathrm{p}$ & $\alpha 1(\tau)$ & $\mathrm{t}$-stat & $\mathrm{p}$ & Half-life \\
\hline 0,1 & $-0,00619$ & $-25,2798$ & 0,000 & 0,09199 & 2,32879 & 0,020 & 0,290497 \\
\hline 0,2 & $-0,00381$ & $-21,4335$ & 0,000 & 0,07471 & 2,45423 & 0,014 & 0,267197 \\
\hline 0,3 & $-0,00237$ & $-15,4703$ & 0,000 & 0,07833 & 2,99744 & 0,003 & 0,272161 \\
\hline 0,4 & $-0,00112$ & $-8,60424$ & 0,000 & 0,05906 & 2,56502 & 0,010 & 0,244997 \\
\hline 0,5 & 0,00000 & $-0,02802$ & 0,978 & 0,05938 & 2,47227 & 0,014 & 0,245466 \\
\hline 0,6 & 0,00117 & 8,27672 & 0,000 & 0,06182 & 2,56067 & 0,011 & 0,249017 \\
\hline 0,7 & 0,00244 & 17,44546 & 0,000 & 0,0777 & 3,55465 & 0,000 & 0,271301 \\
\hline 0,8 & 0,00398 & 20,23824 & 0,000 & 0,07571 & 2,28674 & 0,022 & 0,268574 \\
\hline 0,9 & 0,00632 & 26,74885 & 0,000 & 0,01751 & 0,44783 & 0,654 & 0,171360 \\
\hline
\end{tabular}

Source: Authors' calculation

According to the results of the quantile unit root in Table 12 and Appendix 4 log returns of the CROBEX index from December 2011 to March 2019 exhibit asymmetry. Extreme negative shocks last longer than extreme positive shocks. Higher shocks last longer than smaller shocks and therefore creating a typical U-shape of the autocorrelation coefficients. On the 5\% level significance autoregressive coefficients indicate some level of persistence in each quantile. Therefore the log returns of the Croatian stock market from December 2011 to March 2019 violate the weak form of the efficient market hypothesis.

Considering the structural break which took place in December 2011 time series of CROBEX log return was divided into two periods. Model results for both periods are similar to the full sample model diagnostics. Time series exhibited asymmetries irrelevant of the period selected. Positive shocks lasted longer than negative. In both periods smaller shocks had less persistence then shocks of higher magnitude giving the autocorrelation coefficients a typical U shape. Furthermore, the persistence of the shocks was statistically significant in each quantile consequently rejecting the weak form of the efficient market. These results are complementary to the paper examining the weekly log stock prices of CROBEX in levels and differences. ${ }^{18}$.

18 Bahmani-Oskooee, M., Chang, T., Chen, T. H., \& Tzeng, H. W. (2016). Revisiting the 
Even though results are dependent on data sampling and methodology most of the studies in developing countries suggest some level of predictive behavior. Rejecting the weak-form efficiency hypothesis may inform the traders to question the value of technical analysis and automatic trading strategies. Abnormal profits resulting from a certain level of predictability should always be considered with regards to the associated cost of trading strategy. It should also be stated that the level of market efficiency may change over time. Maturing of the stock market may have a positive effect on market efficiency while crisis usually has a negative effect. Furthermore, it is important to emphasize that certain deviations from the weak form efficient hypothesis may also affect the reliability of asset pricing modeling making the market portfolio less efficient. These are important findings for any stock market investor seeking to capitalize on developing stock markets of post-transition economies of Europe.

\section{CONCLUSION}

This paper adds to the body of literature examining the stock market efficiency of the post-transition economies. Stock markets of the post-transition economies are known for their speculative nature, therefore, questioning the lack of their efficiency. This paper applies a rather innovative quantile auto-regressive approach in testing the market efficiency of the Croatian stock market. Results about the market efficiency are often dependent on data sampling and methodology applied. Previous research using the quantile unit root confirmed the CROBEX value to be non-stationary but this paper further highlights that the $\log$ returns of the CROBEX are stationary. Nevertheless on the basis of the log returns for the stock market in Croatia weak form of the efficient hypothesis market is rejected and therefore revealing the possibility of abnormal returns. Even after accounting for the structural break results stayed robust. Autocorrelation property of the CROBEX log returns was significant in both periods. Furthermore, results also confirmed asymmetries in endogenous shocks. Negative shocks in the log returns of CROBEX lasted longer than positive shocks. In both periods smaller shocks had less persistence then shocks of higher magnitude giving the autocorrelation coefficients a typical $U$ shape. These findings represent an important contribution to the existing knowledge about the efficient market hypothesis and the properties of the post-transition stock markets.

efficient market hypothesis in transition countries using quantile unit root test. Economics Bulletin, 36(4), 2171-2182. 


\section{LITERATURE}

1. Andries, A., Ihnatov, I., \& Sprincean, N. (2017). Do seasonal anomalies still exist in central and eastern european countries? a conditional variance approach. Romanian Journal of Economic Forecasting, 20(4), 60-83.

2. Anghel, D. G. (2017). Intraday Market Efficiency for a Typical Central and Eastern European Stock Market: The Case of Romania. Romanian Journal of Economic Forecasting, 20(3), 88.

3. Bahmani-Oskooee, M., Chang, T., Chen, T. H., \& Tzeng, H. W. (2016). Revisiting the efficient market hypothesis in transition countries using quantile unit root test. Economics Bulletin, 36(4), 2171-2182.

4. Chen, J. and Gupta, A. K. (2000) Parametric statistical change point analysis, Birkhauser

- DOI: https://doi.org/10.1007/978-1-4757-3131-6

5. Čondić Jurkić, I. i Dadić, T. (2008). Investicijski fondovi na hrvatskom tržištu kapitala: strategije trgovanja i kretanje tržišta. Zbornik Ekonomskog fakulteta u Zagrebu, 6 (1), 61-77.

6. Dragotă, V., \& Tुilică, E. V. (2014). Market efficiency of the Post Communist East European stock markets. Central European Journal of Operations Research, 22(2), 307-337.

- DOI: https://doi.org/10.1007/s10100-013-0315-6

7. Hosseinkouchack, M., \& Wolters, M. H. (2013). Do large recessions reduce output permanently?. Economics Letters, 121(3), 516-519.

- DOI: https://doi.org/10.1016/j.econlet.2013.10.012

8. Karanovic, G., \& Karanovic, B. (2018). The day-of-the-week effect: Evidence from selected Balkan markets. Scientific Annals of Economics and Business, 65(1), 1-11.

- DOI: https://doi.org/10.2478/saeb-2018-0005

9. Koenker, R. \& Xiao, Z. (2004). Unit Root Quantile Autoregression Inference. Journal of the American Statistical Association, 99(467), 775-787.

- DOI: https://doi.org/10.1198/016214504000001114

10. Koenker, R. \& Xiao, Z. (2006). Quantile Autoregression, Journal of the American Statistical Association, 101:475, 980-990

- DOI: https://doi.org/10.1198/016214506000000672

11. Marcu, N., Dobrota, C. E., \& Antoneac, R. (2017). An Investigation of the Day-ofthe-week Effect in Conditional Variance at the Bucharest Stock Exchange. Journal for Economic Forecasting, (2), 124-134.

12. Perron, P. The great crash, the oil price shock, and the unit root ypothesis. Econometrica, v. 57, p. 1361-1401, 1989.

- DOI: https://doi.org/10.2307/1913712 
13. Smith, G. (2012). The changing and relative efficiency of European emerging stock markets. The European Journal of Finance, 18(8), 689-708.

- DOI: https://doi.org/10.1080/1351847X.2011.628682

14. Stakić, N., Jovancai, A., \& Kapor, P. (2016). The efficiency of the stock market in Serbia. Journal of Policy Modeling, 38(1), 156-165.

- DOI: https://doi.org/10.1016/j.jpolmod.2015.12.001

15. Tsenkov, V., \& Stoitsova-Stoykova, A. (2017). The Impact of the Global Financial Crisis on the market efficiency of capital markets of south east Europe. International Journal of Contemporary Economics and Administrative Sciences, 7(1-2), 31-57.

\section{APPENDIX}

Appendix 1 Daily log returns for CROBEX index in the period 4.1.20008.3.2019.

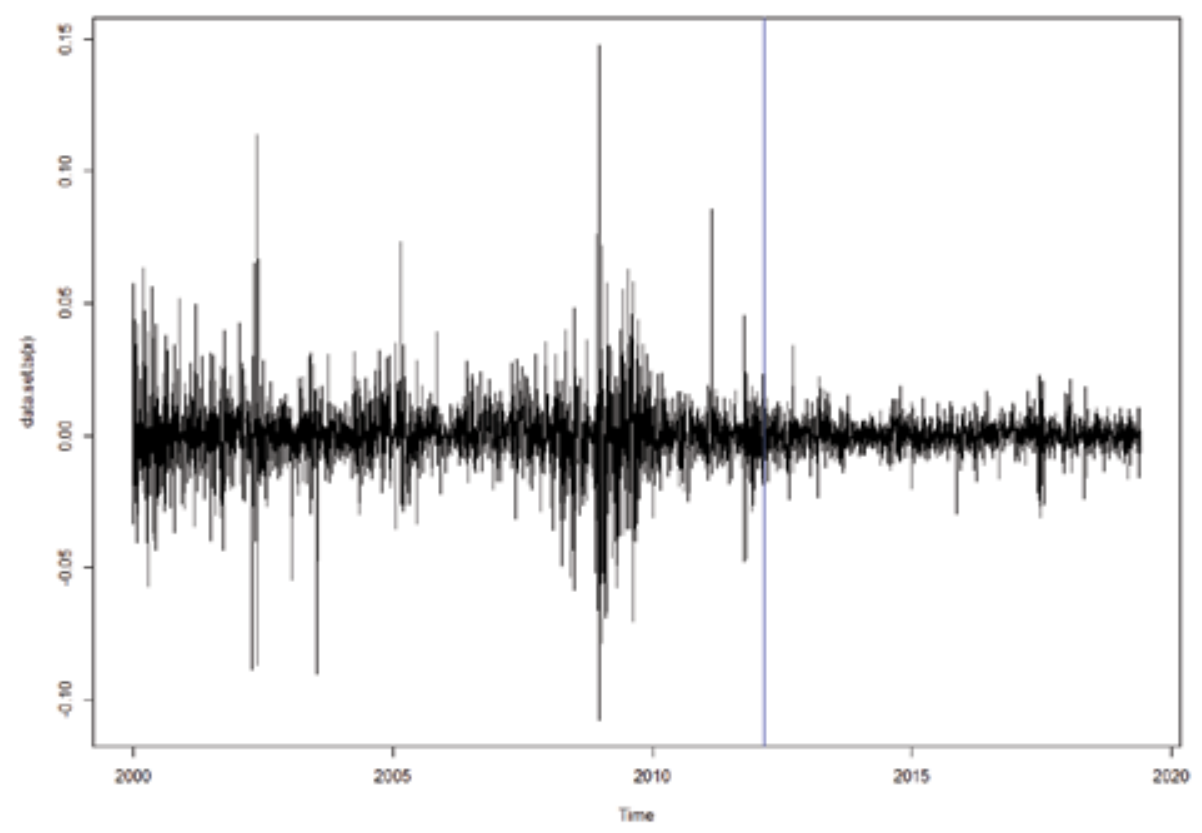


Appendix 2 Quantile auto-regression coefficients: above) sign and magnitude of the shock $\alpha$, below) auto-regression coefficient $\beta 1$ for each quantile, January 2000-March 2019
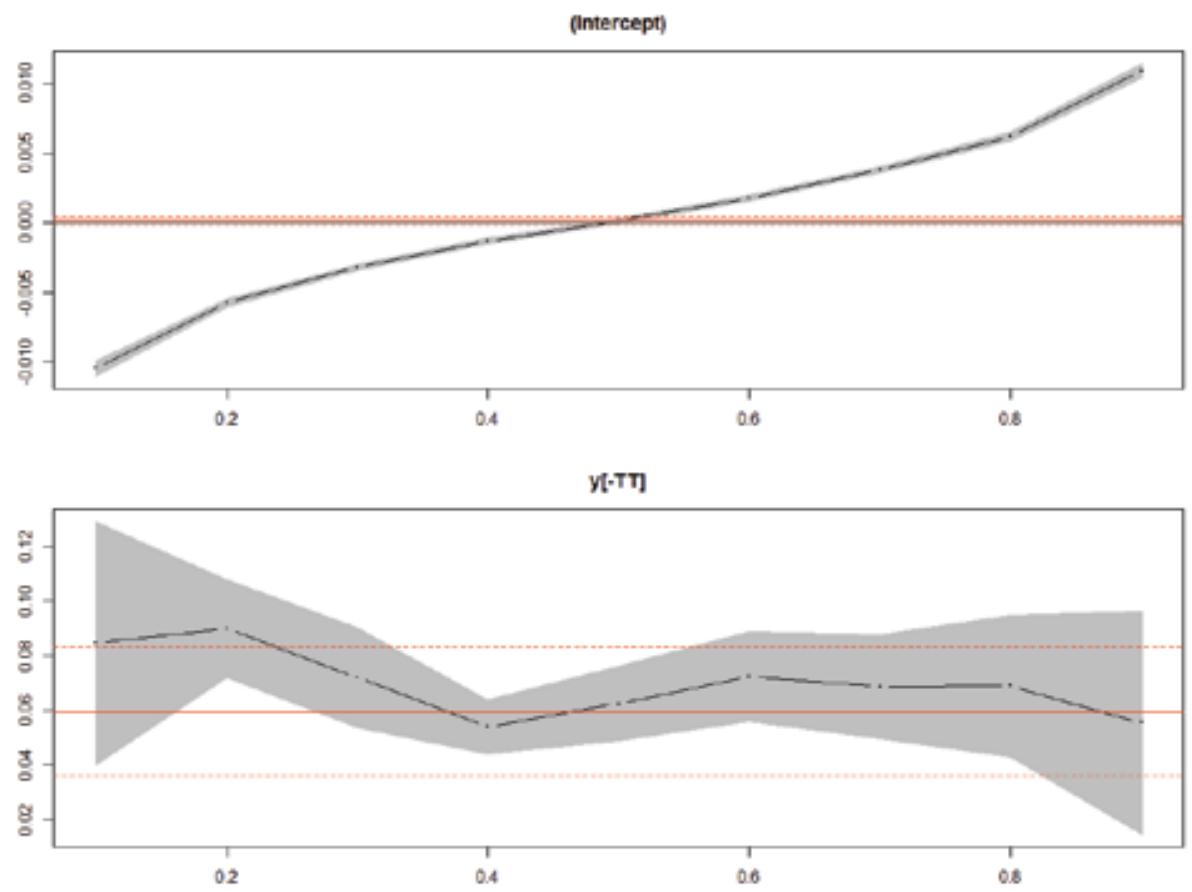
Appendix 3 Quantile auto-regression coefficients: above) sign and magnitude of the shock $\alpha$, below) auto-regression coefficient $\beta 1$ for each quantile, January 2000 - December 2011
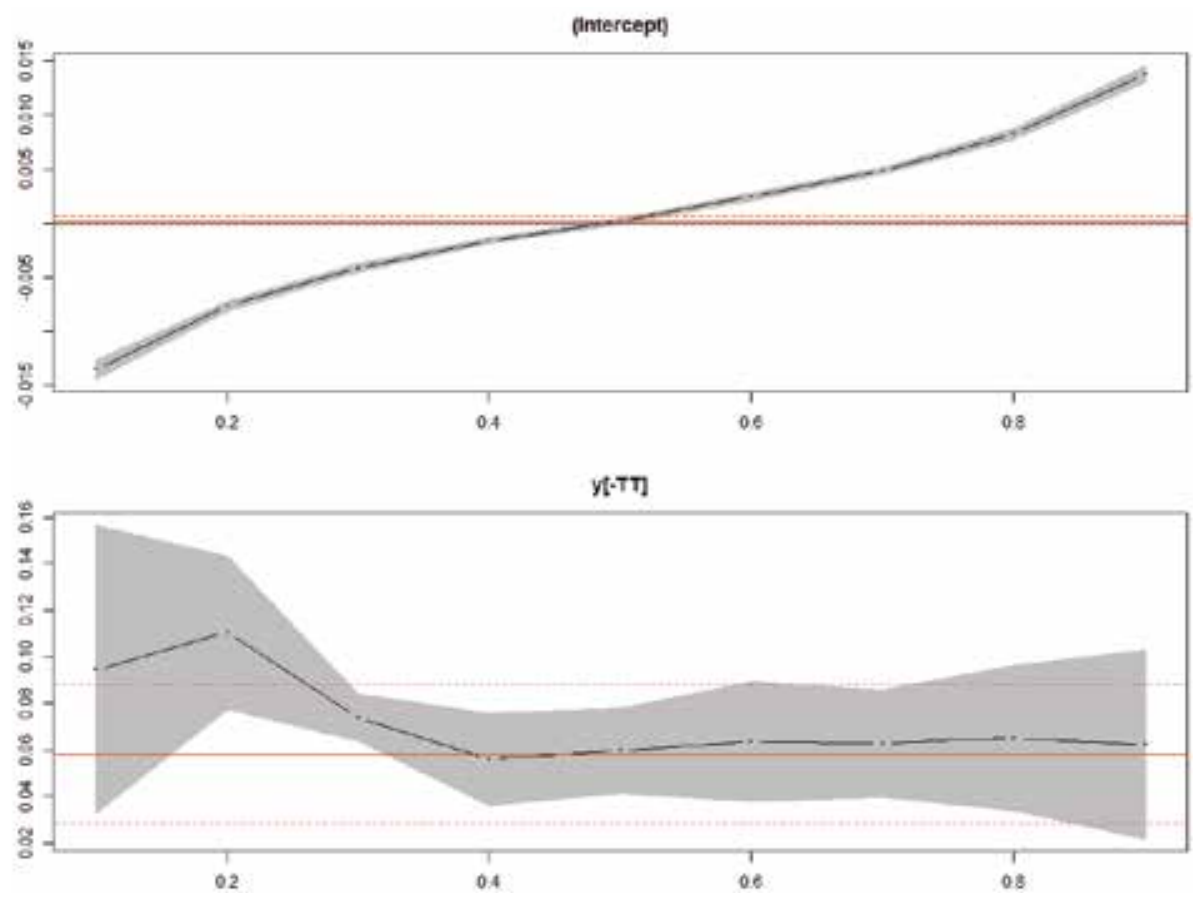
Appendix 4 Appendix 3 Quantile auto-regression coefficients: above) sign and magnitude of the shock $\alpha$, below) auto-regression coefficient $\beta 1$ for each quantile, December 2011-March 2019
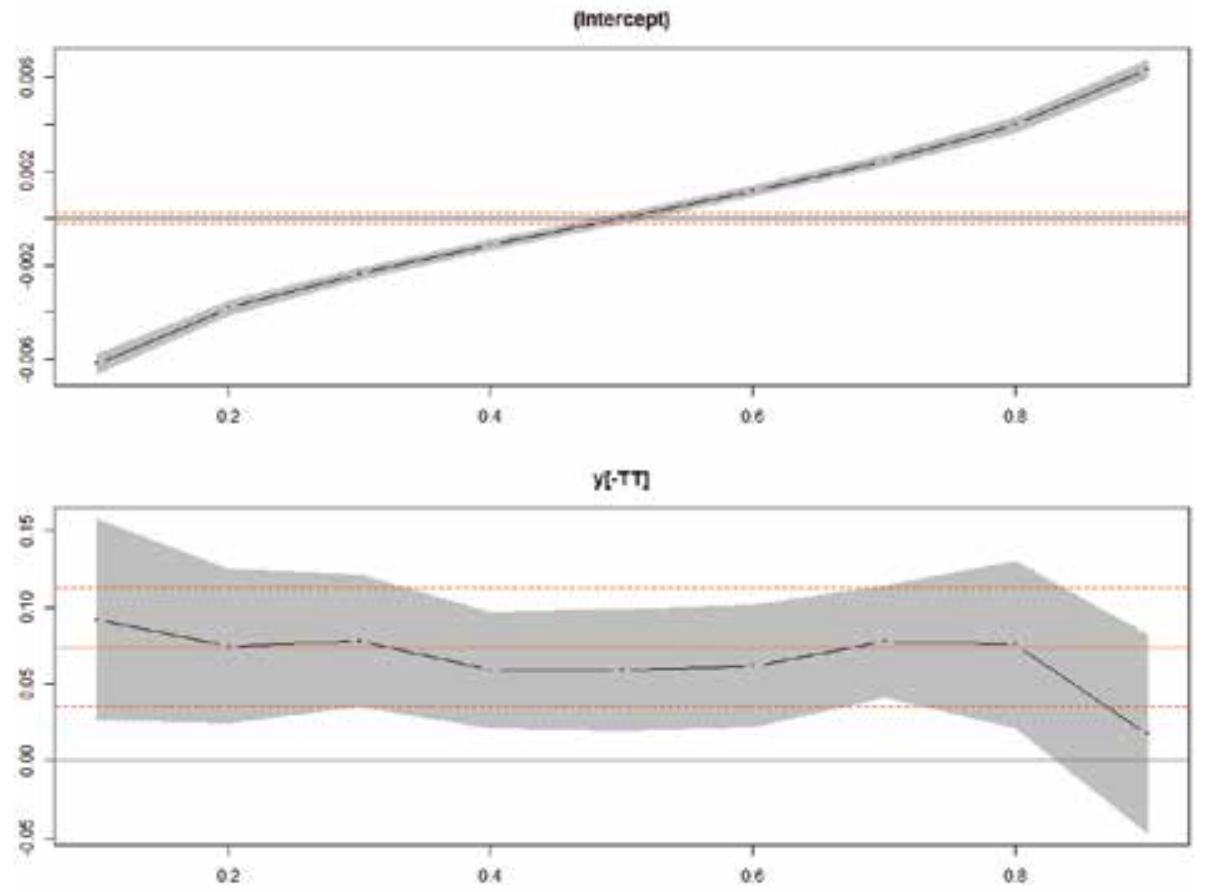